\title{
WestVirginiaUniversity
}

THE RESEARCH REPOSITORY @ WVU

Graduate Theses, Dissertations, and Problem Reports

2018

\section{When Sports Mattered: An Examination of Sports in Mainstream Media}

David Statman

Follow this and additional works at: https://researchrepository.wvu.edu/etd

\section{Recommended Citation}

Statman, David, "When Sports Mattered: An Examination of Sports in Mainstream Media" (2018).

Graduate Theses, Dissertations, and Problem Reports. 6717.

https://researchrepository.wvu.edu/etd/6717

This Thesis is protected by copyright and/or related rights. It has been brought to you by the The Research Repository @ WVU with permission from the rights-holder(s). You are free to use this Thesis in any way that is permitted by the copyright and related rights legislation that applies to your use. For other uses you must obtain permission from the rights-holder(s) directly, unless additional rights are indicated by a Creative Commons license in the record and/ or on the work itself. This Thesis has been accepted for inclusion in WVU Graduate Theses, Dissertations, and Problem Reports collection by an authorized administrator of The Research Repository @ WVU. For more information, please contact researchrepository@mail.wvu.edu. 


\title{
When Sports Mattered: An Examination of Sports in Mainstream Media
}

\author{
David Statman \\ Thesis submitted \\ to the Reed College of Media \\ at West Virginia University \\ in partial fulfillment of the requirements for the degree of \\ Master of Science in \\ Journalism
}
Steve Urbanski, Ph.D., Chair
Robert Blobaum, Ph.D.
David Smith, M.A.
John Temple, M.F.A.
Reed College of Media
Morgantown, West Virginia
2018

Keywords: Journalism, Sports Journalism, News Media, Sports Media Copyright 2018 David Statman 


\section{ABSTRACT \\ When Sports Mattered: An Examination of Sports in Mainstream Media}

\section{David Statman}

Over the last few decades, the fields of sports media and mainstream news media have grown and evolved proportionally to one another, occupying different areas of the same field but having fundamentally different priorities and serving fundamentally different audiences. In recent years, however, a number of high-profile events have caused sports media and news media to blur together, creating an overlap that has not often been analyzed. This study is an examination of how mainstream news media covers stories traditionally covered by sports media, which sports stories mainstream media covers, and the differences between how sports media and mainstream news media cover the same stories. This study was performed by comprehensively researching the sports stories covered throughout the year 2016 by three mainstream news outlets - the New York Times, CNN and NBC News - and comparing them to the work done by ESPN and CBS Sports in the same year.

Over the course of the year studied, mainstream news outlets dedicated the most amount of time covering football and basketball, as well as Olympic sports, owing to the fact that the Summer Olympics in Rio de Janeiro took place in 2016. In addition, an examination of the content of these outlets' coverage of sports during the year showed fundamental differences in how sports and news media approach the same stories. Mainstream news media coverage of sports stories tends to include more context for events and athletes, while sports outlets tend to assume that their audience already knows these things as a given. At the same time, sports outlets are more inclined towards framing stories on crime or social issues through the lens of how the event in question affects the competitive side of sports. Most of the differences stem from mainstream news media's need to reach an audience that might not actively follow sports, and its desire to relate sports events back to issues it already covers. 


\section{Table of Contents}

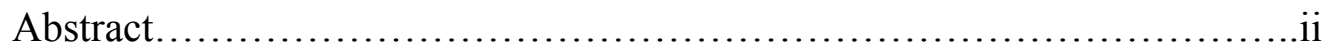

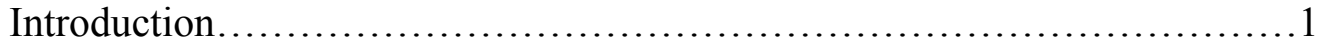

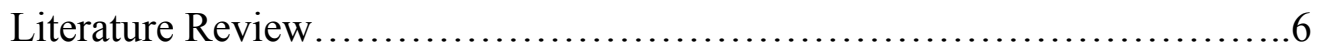

Research Questions....................................................11

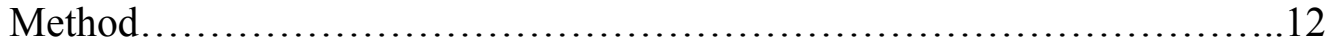

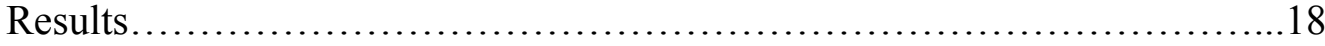

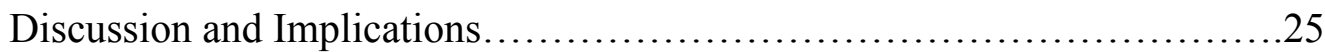

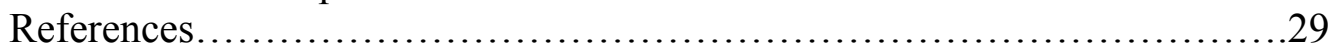




\section{INTRODUCTION}

On September 1, 2016, by the simple act of taking a knee during the "National Anthem," San Francisco 49ers quarterback Colin Kaepernick found himself at the center of a media firestorm. While sports are commonly seen as diversions, pursuits meant to exist outside of the world's problems, athletes have often used their positions to make political and social statements, some classic examples being: John Carlos and Tommie Smith's Black Power salute at the 1968 Olympic Games in Mexico City, or Muhammad Ali's protest against being inducted into military service during the Vietnam War. It was in keeping with this tradition that Kaepernick sent his message: first sitting, then later kneeling during the National Anthem before a number of his team's games throughout the 2016 NFL season to protest racial injustice in America. Although it was a story that started on a football field, the controversy and debates that followed were soon reported in the pages of many major mainstream media outlets (Allen, 2016; Maxwell, 2016) and became a widely talked about story even among people who had little care for football.

Sports and news are often segregated rather cleanly in most media outlets. The traditional design of a newspaper has news occupying the front pages, with sports relegated to its own section. A version of this format, which sees sports reported as its own presentation separated from the main entrée of news, is preserved in some form or fashion in most types of media, be it TV, radio or online. Sports staffs often operate in an entirely separate sphere as well, as the ability to report on sports generally requires a depth of niche knowledge that reporters who focus on news do not have. In a normal 
scenario, news and sports parallel one another, and rarely does coverage of one bleed into coverage of the other. But when a story like the Kaepernick protest emerges, there is a melding of worlds, as space that is normally reserved for politics or war is instead devoted to an NFL quarterback. While this is not the usual state of affairs, it is a phenomenon that can be observed whenever a sports story occurs that is particularly newsworthy.

However, "newsworthy" is term that is often open to interpretation. Different people have different definitions of what makes something newsworthy, and the question of exactly what qualifies a sports story as newsworthy enough to merit mainstream coverage likely will not yield a consistent answer depending on who you ask. But when one takes a look at those stories that have received coverage, one should be able to observe certain trends and features that engender this. What aspects of an event in the sports world cause mainstream news outlets to take notice? By examining past examples of sports stories that have crossed over and received mainstream news coverage, this study will attempt to identify a few major characteristics of sports stories that allow them to attain this level of newsworthiness.

In addition, further insight into the way sports are covered in today's media landscape can be gleaned from closely examining the intersection of traditional news media and sports-centric media, comparing and contrasting which stories the two types of outlets cover, and the ways in which these two types of outlets approach and frame a story. Although a relatively recent phenomenon, sports media has become, in and of itself, an extremely large and powerful industry. Although sports has always been covered by local newspapers - and starting in the late $19^{\text {th }}$ century, by weekly national 
publications such as Sporting News and Sports Illustrated - the history of sports media as a significant factor in the news industry starts with the launching of ESPN in 1979. First incorporated in a former garbage dump in rural Bristol, Connecticut, ESPN was considered the first TV channel dedicated solely to sports, and made possible by the massive growth of cable, ESPN flourished rapidly after struggling financially in its early years (Miller, 2011).

Although other sports-dedicated outlets, such as Fox Sports 1 and the NBC Sports Network, have arisen to contend with ESPN, the "Worldwide Leader" is, indeed, still the leader today among all sports outlets in viewership, name recognition and overall reach (Draper, 2017). Meanwhile, ESPN has gradually grown and shifted to reflect broader trends in how news is covered. The advent of the Internet allowed ESPN to move beyond being merely a broadcast-only outlet, as they grew to maintain a large writing staff and host original reporting on its website, as well as its own print magazine (Miller, 2011). Meanwhile, major broadcast networks such as CBS and NBC - which had always had sports departments, but that might have been restricted to only broadcasting games, hosting specialty shows and providing reports on their main news programs - followed suit and also began to cultivate writing staffs and an online presence. This advance fundamentally changed the face of sports media as a whole, as it allowed for an explosion of new outlets and blogs - most of those being print-centered and focused on new, original reporting and analysis.

As the rise of cable TV news, starting with the birth of CNN in 1980, drove the advent of the 24-hour news cycle, the face of sports media began to change to reflect these new trends. Between outlets such as ESPN, which is constantly broadcasting the 
latest in sports news, and the proliferation of social media, the 24-hour news cycle is as present in sports as it is in the rest of news, as is the fixation on celebrity. Certain athletes and figures receive celebrity coverage in sports media - for instance, ESPN's constant coverage of the basketball-playing Ball family and its self-promoting patriarch LaVar Ball has received comparisons to the news media's obsession with the Kardashian family (Rodgers, 2018).

In turn, certain sports networks' relationships with various leagues and organizations have also created alleged conflicts of interest and affected coverage. Sports networks often draw much of their relevance from broadcasting live sporting events, for which they pay billions of dollars for broadcasting rights. For instance, the National Football League receives $\$ 2$ billion from ESPN annually just for the rights to broadcast Monday Night Football (Sandomir, 2011). This creates a potentially problematic business relationship that makes sports news outlets beholden, in a sense, to these leagues, and it has in the past affected how sports news outlets go about their business. Two examples of this are telling: the NFL successfully pressured ESPN to end its involvement in a PBSproduced documentary on the effect of concussions in football (Van Bibber, 2013), while this past year, Fox Sports was the only major sports network to more or less ignore the allegations of sexual misconduct against former Michigan State University and Larry Nassar, USA Gymnastics doctor (Wagner, 2018), less than two years after it finalized a \$150-million deal for Michigan State's multimedia rights (Solari, 2016). In turn, sports media has had a major impact on the operation of sports leagues: game schedules are routinely built specifically for television (NFL, 2018), and television revenue has been a 
driving force in a wave of conference realignment in college sports over the last two decades (Rittenberg, 2017).

In many ways, the growth and evolution of sports media in the $21^{\text {st }}$ century directly parallels the way mainstream news media has grown and evolved over that time, creating an interesting dynamic in how these two forms of media intersect that merits studying. Sports coverage has always been intertwined with politics and social issues, since those stories represent a major part of the American cultural zeitgeist. Sports also often reflects developments in the "real world." Within the last couple of years, ESPN in particular has drawn more attention to covering stories related to larger social issues - the aforementioned Kaepernick story being a prime example - and has drawn some criticism from the political right over its perceived liberal bias, similar to charges that have been lobbed at CNN, the New York Times and other major news outlets (McCarthy, 2017). These developments would suggest that there might be more of a similarity than one thinks about how sports media and news media approach the same stories, which makes the interplay between these two approaches worthy of investigation. It is for this reason that this study's objective is to shed some light on how sports media and news media parallel each other, and how they interact when they come to cover the same stories. 


\section{LITERATURE REVIEW}

Numerous academic studies have focused on what the news media covers, what it does not cover, and why. Several such investigations have focused specifically on sports media. Looking at what stories are highly covered by sports media can be instructive when trying to discern what stories are covered by the mainstream news media, as only very rarely will the mainstream news media cover a sports story that is not already being intensely covered by the sports media. In 2013, sports journalist Patrick Burns tracked the content of every single 11 p.m. edition of ESPN's SportsCenter, the most-popular and most-highly rated sports news show in America, over the preceding year. His study revealed several interesting trends. First, ESPN awarded more coverage time to franchises seen as more successful and more financially valuable - for instance, over a quarter of SportsCenter's NBA coverage for that year was devoted to the Miami Heat, the defending champions at the time (Burns, 2013).

Burns also found that SportsCenter had a tendency to focus on certain star personalities to the exclusion of many others - as he put it, "Watch the show at the right time of year, and you might come away thinking that there are only a half-dozen or so athletes in the entire world" (Burns, 2013). These sports celebrities received an amount of coverage that did not always correlate to their production on the field, as the media fell in love with certain narratives. For instance, over the year Burnett tracked, Denver Broncos quarterback Tim Tebow received 17 percent more mentions on SportsCenter than fellow NFL signal callers Drew Brees and Aaron Rodgers combined, despite the fact that those two dwarfed Tebow's success on the field. In one extreme case, New York Knicks point guard Jeremy Lin's breakout month of February received so much coverage that, at his 
peak, "the name 'Lin' was by itself nearly 1 percent of all words uttered on SportsCenter." By the end of the year, Lin's mentions on SportsCenter had dropped more or less down to the same rate that they were at before his February spike (Burnett, 2013).

The phenomenon of the sports celebrity does not just impact the way sports media cover stories, but it also spills over into the news media as well. For instance, Tebow's outspoken Christian activism, his star-crossed NFL career and his later foray into professional baseball has received heavy mainstream press attention at every turn (Scott, 2016) - and in the midst of his rapid rise to stardom, Lin was even featured on the cover of Time magazine. There is little difference from the phenomenon of sports celebrities receiving heavy coverage in media from mainstream entertainment or political celebrities. Of course, sports coverage is, at its heart, entertainment - and for some, politics is also a spectacle.

In D.L. Andrews and S.J. Jackson's Sport Stars: The Cultural Politics of Sporting Celebrity (2001), several facets of the sports celebrity phenomenon are examined through the lenses of a number of contemporary sports icons. The book posits that sports celebrity is just another part of a tradition of venerating "heroes" that dates back to ancient civilization, and that has evolved over time with various new types of media. Andrews and Jackson note that today "sports are customarily structured, marketed, mediated and experienced, as contests between identifiable individuals (or groups of individuals) with whom the audience is expected to possess (or develop) some kind of affective attachment," thus creating an environment where certain sports celebrities become paramount figures and shape the way the media cover sports (Andrews \& Jackson, 2001). 
When looking specifically at the coverage of sports stories being covered in mainstream news media, one particularly notable example stands out: American Olympic track medalists John Carlos and Tommie Smith's iconic Black Power salute while on the medal podium during the 1968 Summer Olympics. Carlos and Smith's protest was the predecessor of stories such as Colin Kaepernick's, and that incident alone has inspired studies into how it was covered. Jason Peterson (2009) examined the print media coverage of the Carlos/Smith protest by both sportswriters and news reporters alike. Peterson found that in the early days after the protest, "emotionally biased journalism replaced the journalistic standards of fair and balanced reporting ... rather than pointing out the social legitimacy of the protest, sportswriters buried the message and condemned Smith and Carlos" (p. 116). Accustomed to covering an environment with clear winners and losers, the nuance of the protest was lost to sportswriters but not necessarily to news reporters (Peterson, 2009). When viewing protests in general, past studies have shown that the estimated size of the protest and its perceived importance to the media cycle have the greatest impact on the amount of media coverage it receives, an idea that has been borne out in the examples of Carlos and Smith, and that of Kaepernick (McCarthy, 1996).

There have been past efforts to create newsworthiness models that explain how much a sporting event is covered by the media. In 2009, Jong Hyuk Lee and Yun Jung Choi studied coverage of the 2002 FIFA World Cup in South Korea and Japan to try and determine just that, by studying how much coverage each match of the tournament received against a model measuring the match's "significance and deviance." Their study found that their newsworthiness model was somewhat effective in predicting which matches received more mainstream coverage, although it was more effective in relation 
to traditional media than to online media. Additionally, the study found that the metric of "newsworthiness" did not significantly differ between American and Korean media (Lee \& Choi, 2009).

There have been other studies that specifically focused on the difference between traditional and new media. A 2012 case study of news coverage of Major League Baseball star Manny Ramirez's 50-game suspension for using a banned substance found that while traditional media were more likely to take a broader view of the incident and frame the story in the context of the larger story of steroids in baseball, as well as challenging and criticizing Ramirez, new media tended more towards solely examining the specific case of Ramirez and uncritically representing his explanation for his failed drug test (Whiteside, 2012).

Multiple studies have shown that, in general, the old adage "if it bleeds, it leads" holds true for mainstream media (Cooper, 2000), but that which determines news coverage in general is highly dependent on culture, language and location (Kim, 1996). There does not seem to be a reason that this would not still apply to sports stories being covered by those same mainstream outlets. In fact, sports stories generally rank high among readers' cultural priorities. The audience's receptiveness to sports stories leads newspapers to focus more highly on sports, thus acting as agents of culture (Polumbaum, 2000). Additionally, there have been arguments that this blending of coverage has been served somewhat by the erosion of the distinction between news and entertainment caused by the downfall of news organizations' role as the gatekeepers of information and the fundamental change of the role of media in modern society (Williams, 2000). 
Other studies have examined how major news outlets have covered specific types of sports stories, if not sports stories in general. A study by Jean-Patrick Villeneuvea (2016) found that when covering sports betting stories, news outlets tended to paint the athletes as criminals while framing teams, organizations, and leagues in a more positive light. There were differences from country to country; while French outlets generally focused on the failings of the system in general, British outlets focused more on the greed and weakness of the individual (Villeneuvea). Other studies have found that, for instance, news outlets were more reluctant initially to cover women's sports, seeing them as less newsworthy and struggling to navigate the relationship between athleticism and femininity (Antunovic, 2016). This gap in coverage between the sexes has continued to recur over the course of several decades (Bishop, 2003).

But while past studies have covered certain aspects of media coverage of sports, few (if any) studies have specifically looked at sports stories being covered in spaces that are not devoted to covering sports and how that dynamic works. This research will attempt to fill that gap. 


\section{RESEARCH QUESTIONS}

This research aims to delve into the dynamics that intertwine sports writing and news writing and which types of sports stories seemingly apply the most to the everevolving concept of newsworthiness. Sports media and news media have fundamentally different priorities and serve different audiences, but journalistic standards and common interests create an intersection that begs exploration. As such, this study intends to answer the following research questions:

RQ1: What types of sports stories tend to receive more coverage from mainstream news media?

RQ2: In what ways does coverage of these stories differ between sports media outlets and mainstream news media outlets?

RQ3: Which categories of sports-related stories are more likely to be covered by mainstream media but overlooked by sports media? 


\section{METHOD}

In order to address these research questions properly, this study required the researcher to not only to find what sports stories were reported upon by mainstream news media outlets, but also to examine their content and the differences between how those same stories were covered by sports media outlets, thus necessitating multiple stages of research. To start, I established a sample size encompassing the year 2016, which was the most recent completed year at the time the study was initiated. The basic parameters of the study also included which outlets to consider. Three mainstream media outlets and two sports outlets were selected.

For the three mainstream media outlets, the New York Times, CNN and NBC News were selected, all three chosen for their online presence and their general prominence in mainstream news media. The two sports outlets were ESPN and CBS Sports, selected for similar reasons. Additionally, these specific outlets were chosen because of the desire to have five sources completely independent from one another - for instance, NBC News directly replaced ABC News due to the fact that ABC News and ESPN are both owned by the Walt Disney Company. During 2016, the New York Times was self-owned, CNN was owned by Turner Broadcasting, NBC was controlled by Comcast and CBS Sports was controlled by the larger CBS Corporation, ensuring that all five would be entirely independent of each other.

The fact that there were only two sports outlets, as opposed to three news outlets, also reflects this desire. The number of sports outlets that cover the breadth of national sports is already relatively limited, with several of those either not being 
independent from the chosen news outlets (for instance, Bleacher Report, owned by Turner Broadcasting along with CNN) or having pivoted away from written content (Fox Sports). In the end, it was determined that only two sports outlets fit those requirements: ESPN and CBS Sports.

From there, the Internet Archive's Wayback Machine was used to examine each day of 2016 to see which sports stories were reported upon and received relatively high placement on mainstream news sites. While the definition of "high placement" varied from site to site, depending on how each outlet's website was laid out, articles that were counted as having high placement were located near the top of the website's front page - "above the fold," to use newspaper vernacular. With these parameters set, the front page of the New York Times, CNN and NBC News websites was viewed for every day of 2016, aggregating every article that received high placement on their websites.

Although the Wayback Machine had archived representations of every single day of 2016 for the outlets in question, and usually multiple archived versions per day, the times of day varied. An effort was made to look at each website at as close to the same time of the day as possible, choosing to aim for as close to 6 p.m. every day as was available, as it tends to be a time of higher traffic for news sites as people get home from work. The researcher surmised that if ever a news site had a story it wanted its audience to see, it would likely be up at that time. Afterwards, these articles were compiled into a list and sorted into nine categories, several of which were added during the sorting process. 
The nine categories were: crime (which encompassed all coverage of arrests and criminal proceedings involving athletes or sports figures), social issues (encompassing coverage of athletes or athletic events intersecting with larger societal topics, e.g. racism or the gender wage gap), coverage of a competition (e.g. coverage of the Super Bowl, or anything relating to the actual sports side of sports), business (for instance, new stadium deals or TV rights deals), doping, concussions (as the ongoing concussion crisis in contact sports did not seem to directly fall into any other category, but merited a category of its own), deaths of famous sports figures, sports media itself (one example: ESPN's suspension of baseball analyst Curt Schilling for transphobic social media posts was a story of its own that was covered by several news outlets) and human interest (a miscellaneous category that was for any story that a news outlet deemed interesting enough to cover but that did not fit into or comprise any category of its own). The same test was run with a secondary coder, and afterwards Cronbach's alpha was performed on the two datasets to establish whether the data was consistent and reliable.

The study began with five original categories: crime, social issues, competition coverage, business and human interest, which were chosen after taking a sample survey of several dates in 2016 prior to the start of the study, as they were the most common types of stories observed. However, as the story-gathering process began, the doping, concussions, deaths and sports media categories were added, as it became clear that other categories were needed to neatly fit a large number of stories found during the study. For instance, doping became a very highly covered subject leading up to and during the 2016 Olympics, and the researcher did 
not feel comfortable lumping its stories in with any of the original categories, necessitating the creation of a new one.

After the categories were clearly distinguished and the coding process done, the process was repeated several times on a smaller scale, this time separated by news outlet, in order to determine which particular outlets covered which types of stories and if there were differences across the organizations that were studied. Afterwards, another round of coding was performed, this time grouping the articles by sport, instead of by topic, across all outlets studied. Although categorizing the outlets by sports was relatively straightforward - determining whether an article is about football or basketball requires only a cursory look - it still required that some subtle distinctions be made.

For instance, the researcher combined many different sports into a broader "Olympic sports" category, as the $31^{\text {st }}$ Summer Olympics in Rio de Janeiro were held in 2016. This was done to consolidate a number of articles that were all covering the same event. However, the heavy coverage of the arrest and trial of Brock Turner, a Stanford University swimmer who was convicted of rape, necessitated the separate creation of an "amateur swimming" category. Although swimming is an Olympic sport, Turner was not an Olympian and the notoriety of this story was in no way tied to the Olympics, so it seemed improper to place the Turner story into a category that was solely devoted to containing stories on the Summer Olympics.

To compile another one of the study's three research questions, particular focus was placed on several of the sample's topic categories. In the past, circumstances have arisen where sports media outlets have neglected to cover 
controversial stories. For instance, ESPN notably refused to cover Pittsburgh Steelers quarterback Ben Roethlisberger's sexual assault accusation in 2009, or more recently, Fox Sports' failure to cover sexual misconduct accusations surrounding former USA Gymnastics doctor Larry Nassar and the Michigan State University athletic program. These occurred amidst accusations of conflicts of interest due to business relationships between the media outlet and the organizations in question. To further investigate how these relationships might have functioned in 2016, several categories that were deemed "potentially controversial" were isolated. In other words, if covered, they could reflect poorly on the organizations. The categories in question were crime, doping and concussions. Each article in those categories was examined to see which were also covered by sports outlets, to see if there was any discrepancy.

The final stage of research required a more direct, textual study of the articles found in the sample, requiring me to examine a smaller cross-section of the sample. The overall sample consisted of 524 articles, which in the end proved to be too large to allow for a close examination of every single one. Ultimately, the decision was made to draw this cross-section from the stories found in the sample that were covered by more than one of the mainstream news media outlets involved in the study at the time of their occurrence. This cut the overall sample down to 51 stories, each with anywhere between three and five articles covering the story, making the sample size much more manageable. Each of the articles covering these 51 stories was then studied, searching for any major differences between the methods in which mainstream media and sports media covered these stories, how 
they framed these stories, and what information they chose to include and what they chose to leave out of these stories. 


\section{RESULTS}

The initial expectations were that mainstream news media would tend to cover the intersection of sports and politics, social issues and the like. It was believed that in general, the media was more likely to cover stories when the world of sport melded into the realms that mainstream media usually covers instead of actually offering coverage of sporting events. However, this study found that out of the 524 stories, competition coverage had the highest percentage (37.6\%) of any of the categories. The other most significant percentages are represented by crime $(23.3 \%)$ - the celebrity status granted to athletes and sports figures is enough to make the most mundane of arrests into stories - and social issues (11.8\%) in a year that featured the explosion of the national anthem protests across the sports landscape and the Rio de Janeiro Olympics drawing attention to social inequality in Brazil.

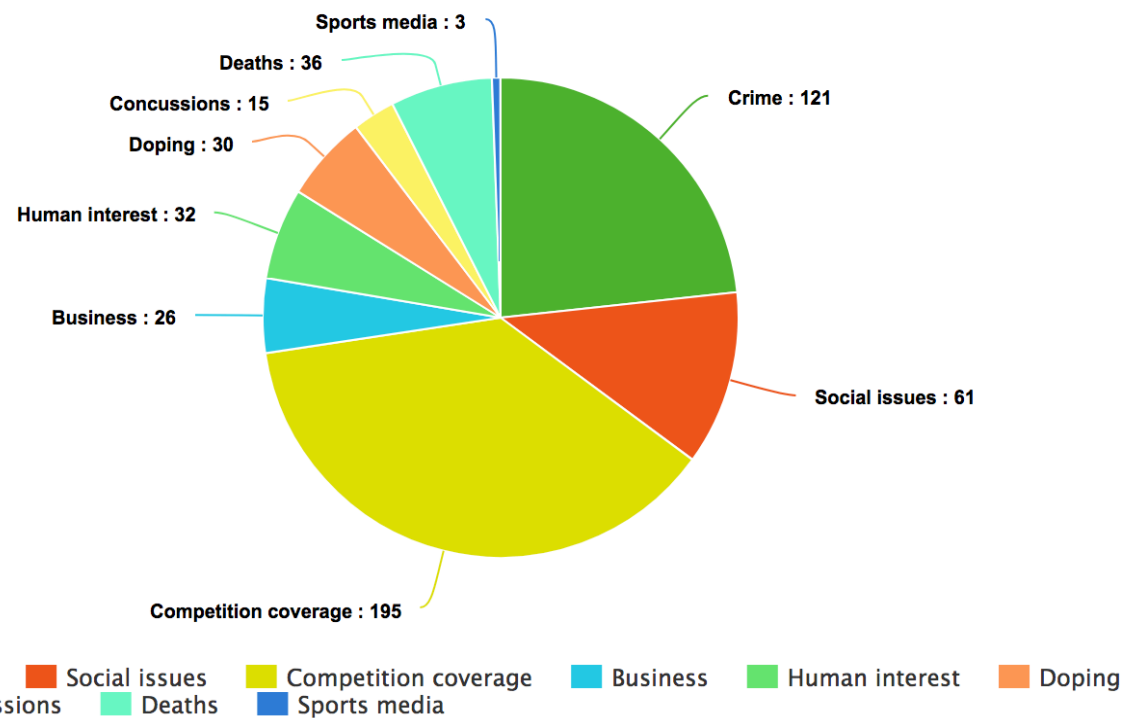

However, these results vary widely from outlet to outlet. The fact that competition coverage commands the largest share of the overall sample is balanced 
mainly by the fact that over half of the sports stories that received high placement appeared in the New York Times - a newspaper with a traditional-style sports staff that actively covers sports across the country, but also has a particular focus on its local market. For CNN, crime (32.4\%) received the largest share of the pie, followed by competition coverage (28.2\%) and social issues (12.7\%). Meanwhile, NBC News finished with an even tie between crime and competition coverage, both at 29.3\%, followed by social issues (12.5\%) and deaths (10.9\%). Clearly, sports competition coverage in the New York Times skewed the overall results somewhat, even if competition coverage remained one of the top categories across different outlets.

However, it should be noted that when compared with data from a secondary coder, there were some relatively sizeable differences that led to a negative value of -.114 in Cronbach's alpha, meaning that the data was unreliable in such a relatively small sample. However, although the initial alpha indicated there was no agreement among the coders, removing the human interest/miscellaneous variable increased the alpha significantly to 0.236 , suggesting that there was little to no correlation between those variables, and further removing the social issues and business variables further increased the alpha to .378 , which is considered "medium" reliability. These three variables were removed because they appeared to be three of the broadest categories with the most room for confusion - many articles placed into miscellaneous could have found a home in other categories, while business and social issues often overlapped with competition coverage, crime, and each other. Still, the results from the secondary coder retained the same basic structure as the original dataset: competition coverage having the highest percentage of the results, 
then followed by crime and social issues. Therefore, it seems likely that while the individual percentages may change from coder to coder, the overview of the results will generally stay the same.

These results were undoubtedly weighted heavily by the most major sporting event of 2016: the Games of the XXXI Olympiad, which dominated the public consciousness for several weeks and earned major coverage from mainstream news and sports outlets alike. The events of the Summer Games were often a top story while the competition was running, with a particular focus on the performance of American athletes. This, in turn, heavily weighted the results of which sports were covered the most during 2016. As was expected, no game was more omnipresent in the public eye than football (29.4\%), the most-popular sport in America. Olympic sports (25.8\%) ran a relatively close second, with interest peaking during the actual Olympic Games and trailing off significantly after.

Basketball came up third with $12.2 \%$, while, rather interestingly, America's national pastime of baseball wound up tied with soccer - a game that has long struggled to gain a foothold in the American popular consciousness - at 7.6\%. Tennis was also a relatively strong focus, as the performance of certain star athletes such as Serena Williams and Roger Federer, and the results of the game's major championships often received high coverage from mainstream news sources. A relatively large portion was also allotted to "miscellaneous sports," a highly varied category that included a number of sports that received five or fewer stories. There were also several stories that would not fit into any one sport, including articles on firings in sports media and several stories on the business practices of daily fantasy 
sports websites. These are represented in the results under the category marked as "N/A."

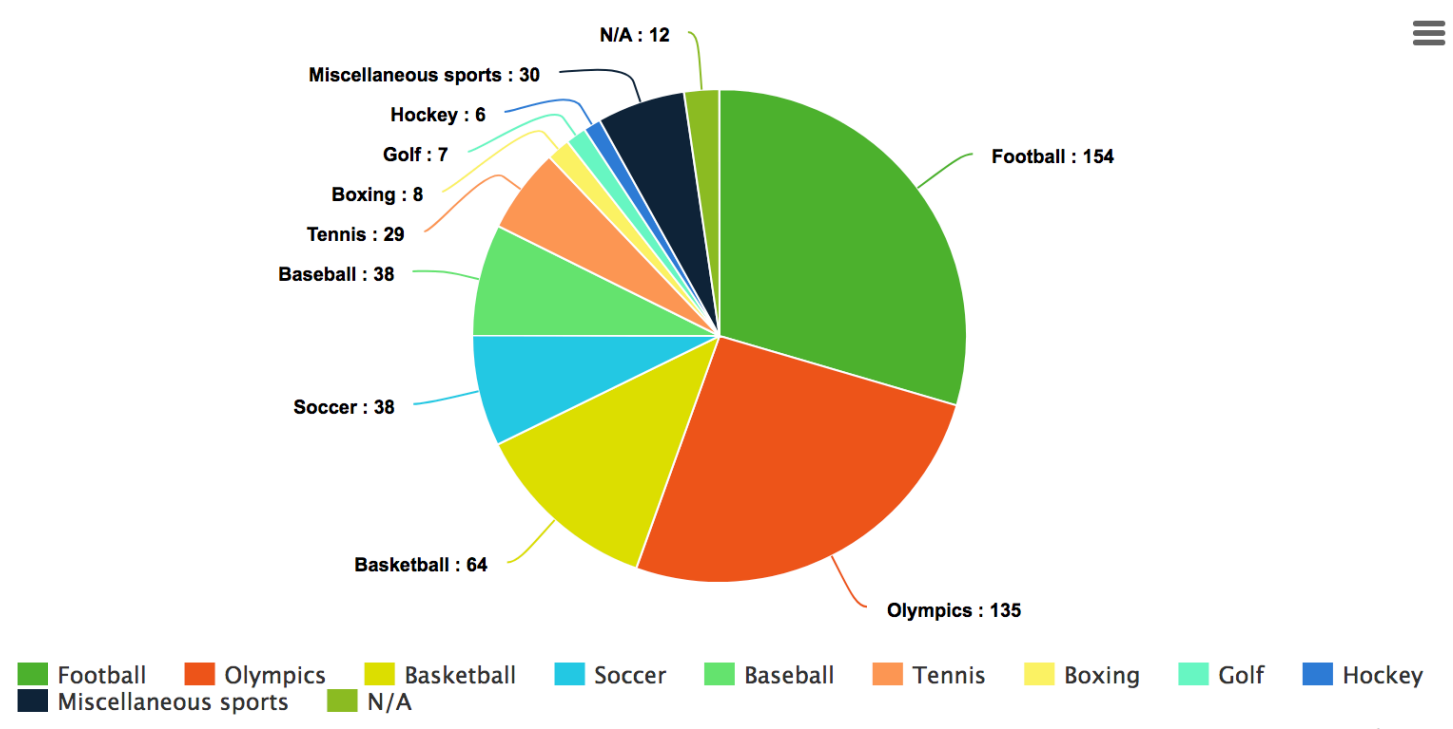

When examining the differences between how sports media and mainstream news media cover the same stories, several distinctions between the two approaches were detected. One of the main differences is mainly a byproduct of the differences in output. When ESPN covers, for instance, the St. Louis Rams NFL team announcing its move to Los Angeles, it comes after months of reporting on the same story at every stage, from the move's conception to its actual execution. That is not the case when CNN reports on the move - while the very notion of an NFL team moving cities is a major story in sports media from the beginning of the process, it does not receive the same kind of coverage throughout from mainstream news media. The CNN audience has not necessarily been exposed to the overall narrative of the story over the time it has developed, and thus requires more overall background information. 
Keeping with the same example, articles on the Rams move appearing in mainstream news media were generally more focused on informing readers of the process leading to the move being announced, while also providing heavy background information on the history of the NFL in Los Angeles and the history of NFL expansion in the time since Los Angeles last had a professional football team (Belson, 2016; Byers, 2016). Sports media assumes that the reader already knows this information, as if either the reader has picked pieces of the story up along the way or is already invested and familiar with it, since the sports outlet has covered the story from its birth. Meanwhile, a news outlet only covers the story when it reaches a certain point of mainstream interest, which means their audience has not been exposed to the story throughout the process. These differences in focus were one of the most common trends observed throughout the entire year: for instance, the New York Times' coverage of New England Patriots quarterback Tom Brady's court appeal of his suspension over the "Deflategate" scandal heavily focused on the background of the case, and even contained a brief overall history of players clashing in court with leagues in the past (Belson, 2016) but ESPN's coverage focused almost entirely on the happenings of the court case itself (Brandt, 2016).

This study also found that sports media tends to assume that their audience understands certain processes and that they do not need explaining, which is not always the case with mainstream media. As an example, when covering NBA superstar Kevin Durant's decision to sign with the Golden State Warriors in July 2016, the New York Times felt the need to describe to its audience how NBA free agency works and why basketball fans follow it so intensely (Hoffman, 2016), 
something that ESPN or CBS Sports does not feel the need to do (Young, 2016;

Berger, 2016). This was also present in stories regarding a number of other major sports events in 2016, such as the Brady suspension (Belson, 2016) and the Los Angeles Rams move as well (Byers, 2016).

The fact that sports media and mainstream news media are writing for fundamentally different audiences, with fundamentally different interests, greatly affects the content and focus of their articles as well. This study found that sports media coverage on stories related to social issues or matters that extended beyond sports were often likely to include analysis of how they affected what was going to happen on the field, while mainstream news rarely covered that same angle - for instance, ESPN's coverage of the beginning of Kaepernick's National Anthem protest also included information on his performance in the game and how the protest affected the battle for the San Francisco 49ers' starting quarterback spot (Wagoner, 2016). Meanwhile mainstream news media tended to focus more on the racial history of the National Anthem (Schuessler, 2016) and its resonance within American society at large (Martin, 2016). In another example, when Major League Baseball star Jose Fernandez was killed in a boating accident in September of 2016, ESPN and CBS Sports heavily focused on the effect his death had on his team, their schedule, and Fernandez's excellent performance on the mound (Walker, 2016; Anderson, 2016), factors that were glossed over or not present in mainstream news accounts of his death (Alvarez, 2016; Hume, 2016).

Examining several specific categories also yielded some results regarding the differences in what mainstream media and sports media find to be newsworthy. By 
and large, the sports stories that mainstream media outlets saw to be important were viewed the same way by sports media, which was expected. This includes more controversial topics such as the concussion crisis in football. Despite ESPN and CBS Sports's potentially problematic business relationships with the NFL and the NCAA, sports outlets tended to cover the concussion crisis just as hard, if not harder, than mainstream media outlets notwithstanding the negative light in which the subject matter paints the game of football.

However, one particular category received much more attention from mainstream news media than sports media in 2016, namely doping, which became the center of a major controversy when a full Olympic ban was considered for Russia after a massive state-run doping scheme was uncovered. (Ruiz, 2016) While multiple mainstream news outlets surveyed covered the story heavily at every step of the way, along with several other doping-related stories during the course of the year, it was found that those same stories received comparatively little attention from ESPN and CBS Sports, with ESPN in particular only giving placement to the Russia story when the International Olympic Committee officially announced that there would be no full Olympic ban. Even then, the article posted on its website was a wire report from the Associated Press and was not bylined (ESPN, 2016). This discrepancy could be linked to the geopolitical climate, as the story of illicit Russian doping has a thematic link to the larger story of alleged Russian subterfuge during the American presidential election that became a massive news story throughout 2016, but which does not connect to what sports media typically covers. 


\section{DISCUSSION AND IMPLICATIONS}

The purpose of this study was to shed some light on what sports topics mainstream media are most likely to cover, and to explore the differences in approach between sports media and mainstream news media. The results

pertaining to RQ1 were undoubtedly skewed somewhat by the fact that 2016 was an Olympic year, and as the Olympics is one of the largest and most-popular sporting events in the world, they received heavy coverage during the weeks leading up to and during the event whereas during other years, Olympic sports generally receive little (if any) coverage. In 2016, almost 56 percent of all Olympic sports articles appearing in mainstream news media ran during the months of July and August. However, this study showed that in 2016 at least, football and basketball reigned supreme in the public consciousness throughout the year. It also demonstrated that the largest share of stories that mainstream news is likely to cover involve the actual competition side of sports. Clearly, mainstream news media outlets believe that their audience will still be interested in coverage of major sporting events without actually going to a sports-centric outlet, but they are extremely likely to cover a story if it intersects in a major way with crime or social issues.

When directly examining the text of these articles while trying to answer RQ2, it became evident that most of the differences in approach between sports and news media were results of the fact that they have fundamentally different priorities and audiences. People who rely on ESPN for their news are looking specifically for one thing: sports news and analysis, which allows ESPN to delve deeper into topics and establish a baseline of knowledge for a story that it will often assume a reader 
already possesses. Many sports fans specifically do not want intrusions of the "outside world" into their topic of interest. They want sports to be an escape - past studies have shown that escapism is one of the predominant motivations for sports fans to engage in this hobby (Wann et al., 1999; Withey, 2013) - and sports media outlets have often received backlash in the past for covering stories that intersect with real-world issues (McCarthy, 2017). When covering these stories, however, sports media attempts to bridge that gap by focusing more on the on-field aspects of a story, thus fulfilling the outlet's original purpose of covering sports in a way that is not relevant to the purpose of mainstream news outlets.

Examination of the results pertaining to RQ3 revealed that mainstream news outlets also covered doping, specifically the Russian Olympic doping scandal, much heavier than the major sports outlets. As previously speculated, this might have been because of a perceived tie-in to alleged Russian duplicity in the American presidential election that year, but the heavier coverage of doping was not limited to just that story. Further study could perhaps focus specifically on news media coverage of doping in sport to further get at why this disparity exists. Additionally, it was found that conflicts of interest regarding topics such as concussions or crime were not as prevalent as previously expected, as sports media covered those topics as hard, or harder, than news media.

Mainstream news outlets are not beholden to any obligation to keep their audience informed on the latest developments in the world of sports, and thus pick and choose what stories they feel are newsworthy enough to cover. Oftentimes, this means picking up sports stories that intersect in some way with stories or trends 
that they have already deemed highly newsworthy. For instance, one could argue that Kaepernick's protests would not have received as much publicity if it did not intersect with how news media was already covering race relations and the policing of black communities in America. Similarly, the Baylor rape scandal, which escalated when it was reported that Baylor University had ignored numerous accusations of sexual assault by football players, might not have occupied the public consciousness as much if it had not coincided with a time where campus rape culture was already a hot issue. This directly informs much of mainstream news media's coverage of sports, as they apply their existing standards of newsworthiness on sports in a way that does not exist in sports media, as its audience is not there specifically to learn about sports.

While this study was able to provide some insight on how news media approach sports and the dynamic between sports and news media, there were limitations that should be noted for future studies. It may do well to once again examine what stories news media covers in a year that do not contain the Olympics, which skewed the results and dominated a large amount of the year. Also, while this study offered a broad look at everything that was covered over the course of the year, a future study may want to hone that focus directly on one or two specific issues, to see how coverage differed in a finer space, which will perhaps lead to a greater and deeper understanding of the dynamics between sports and news media. In addition, the category system could have been further tightened to produce results with larger agreement and avoid the initial Cronbach's alpha issues. This could potentially be achieved by further dividing the categories, specifically the 
business and social issues category, into more narrow topics. This could potentially avoid some confusion over which articles fit into what topic and allow for more uniformity between coders. 


\section{REFERENCES}

Allen, N. (2016, September 18). Colin Kaepernick: NFL Black Lives Matter protests recall rebellious spirit of 1960s sporting greats. Retrieved August 29, 2017, from http://www.telegraph.co.uk/news/2016/09/18/colin-kaepernick-nfl-black-livesmatter-protests-recall-rebellio/

Alvarez, L. (2016, September 25). Marlins Pitcher Jose Fernandez Is Killed in Boating Accident. Retrieved February 14, 2018, from

https://www.nytimes.com/2016/09/26/sports/baseball/jose-fernandez-deadmiami-marlins.html

Anderson, R.J. (2016, September 25). Marlins pitcher Jose Fernandez killed in boating accident. Retrieved February 14, 2018, from https://www.cbssports.com/mlb/news/marlins-pitcher-jose-fernandez-killed-inmiami-boating-accident/

Andrews, D. L. and S. J. Jackson, eds (2001) Sport Stars: The Cultural Politics of Sporting Celebrity. London: Routledge.

Antunovic, D. (2016). 'You Had to Cover Nadia Comaneci': 'Points of Change' in Coverage of Women's Sport. International Journal of the History of Sport, 33(13), 1551-1573.

Belson, K. (2016, April 25). N.F.L. Wins Appeal, and Tom Brady Has Little Recourse. Retrieved March 24, 2018 from https://www.nytimes.com/2016/04/26/sports/tom-brady-deflategate-newengland-patriots-suspension-reinstated.html

Belson, K. (2016, January 12). Rams Moving to Los Angeles Area, and Chargers Could Join Them. Retrieved February 14, 2018, from https://www.nytimes.com/2016/01/13/sports/football/rams-moving-to-losangeles-area-and-chargers-could-join-later.html

Berger, K. (2016, July 4). In a perfect storm, Durant joins Warriors and changes the course of NBA history. Retrieved February 14, 2018, from https://www.cbssports.com/nba/news/in-a-perfect-storm-durant-joins-warriorsand-changes-the-course-of-nba-history/

Bishop, R. (2003). Missing in action: Feature coverage of women's sports in Sports Illustrated. Journal of Sport and Social Issues, 27(2), 184-194.

Brandt, A., Reiss, M. and Rovell, D. (2016, April 27). Tom Brady has 4-game suspension upheld, not ready to accept ruling. Retrieved March 24, 2018 from http://www.espn.com/nfl/story/_/id/15353950/tom-brady-new-england-patriotsfour-game-suspension-deflategate-reinstated-appeals-court 
Burns, P. (2013, July 26). What I Learned From A Year Of Watching SportsCenter. Retrieved August 29, 2017, from http://deadspin.com/what-i-learned-from-a-yearof-watching-sportscenter-5979510

Byers, D. (2016, January 13). NFL gives Rams approval to return to LA, Chargers may join them. Retrieved February 14, 2018, from http://money.cnn.com/2016/01/12/news/nfl-los-angeles/index.html

Cooper, C. P., \& Roter, D. L. (2000). " If it bleeds it leads"? Attributes of TV health news stories that drive viewer attention. Public Health Reports, 115(4), 331.

Draper, K. (2017, August 30). Something New Amidst the Turbulence at FS1. Retrieved February 14, 2018, from https://www.nytimes.com/2017/08/30/sports/fs1-first-things-first-fox-news.html

ESPN.com news services. (2016, July 24). Russia won't be fully banned from Olympics. Retrieved February 14, 2018, from http://www.espn.com/olympics/story/_/id/17134646/international-olympiccommittee-decides-full-olympic-games-ban-russia

Hoffman, B. (2016, July 4). Kevin Durant to Join the Golden State Warriors. Retrieved February 14, 2018, from https://www.nytimes.com/2016/07/05/sports/kevindurant-to-join-the-warriors.html

Hume, T. (2016, September 26). Miami Marlins star pitcher Jose Fernandez killed in boating accident. Retrieved February 14, 2018, from http://www.cnn.com/2016/09/25/us/mlb-pitcher-jose-fernandezdead/index.html

Jong Hyuk, L., \& Yun Jung, C. (2009). News values of sports events: an application of a newsworthiness model on the World Cup coverage of US and Korean media. Asian Journal of Communication, 19(3), 302-318. doi:10.1080/01292980903039012

Kim, K. and Barnett, G.A. 1996. The determinants of international news flow: A network analysis. Communication Research, 23: 323-352.

Martin, J. (2016, September 2). Colin Kaepernick continues anthem protest before Chargers game. Retrieved February 14, 2018, from https://www.cnn.com/2016/09/01/sport/nfl-preseason-49ers-chargers-colinkaepernick-national-anthem/index.html

Maxwell, F. (2016, September 22). Silence From Kaepernick Critics Speaks Volumes. Retrieved August 29, 2017, from http://www.huffingtonpost.com/entry/57e2f47fe4b05d3737be53de?timestamp=1 474507429354 
McCarthy, J. D., McPhail, C., \& Smith, J. (1996). Images of protest: Dimensions of selection bias in media coverage of Washington demonstrations, 1982 and 1991. American Sociological Review, 478-499.

McCarthy, M. (2017, June 6). ESPN's own study indicates big chunk of viewers perceive network has liberal bias. Retrieved February 14, 2018, from http://www.sportingnews.com/other-sports/news/espn-political-bias-liberalconservative-langer-research-associates-hank-williams-jr-colin-kaepernick-curtschilling/5goo5xpn3hhd1eiwiqm9vmahl

McGuire, J., Murray, R., \& Ketterer, S. (2015). Sports department vs. news department: editorial control in television newsrooms. The Sport Journal, 18.

Miller, J. (2011). Those Guys Have All the Fun: Inside the World of ESPN. New York, NY: Little, Brown and Company.

NFL.com (2017). Creating the NFL Schedule. Retrieved March 22, 2018, from https://operations.nfl.com/the-game/creating-the-nfl-schedule/

Peterson, J. (2009). A 'Race' for Equality: Print Media Coverage of the 1968 Olympic Protest by Tommie Smith and John Carlos. American Journalism, 26(2), 99.

Polumbaum, J. 2000. News for the culture: Why editors put strong men hitting baseballs on page one. Newspaper Research Journal, 21(2): 23-39.

Rittenberg, A. (2017, June 27). Save the date: All eyes on 2023 for conference realignment. Retrieved March 22, 2018, from http://www.espn.com/collegefootball/story/_/id/19743196/why-2023-next-big-date-conference-shuffling

Rodgers, J. (2018, January 8). Steve Kerr calls LaVar Ball the 'Kardashian of the NBA,' criticizes ESPN. Retrieved February 14, 2018, from http://www.sportingnews.com/nba/news/steve-kerr-lavar-ballkardashian/1uhhena3kf84t12zg9l8fel1qr

Ruiz, R. (2016, June 17). Russia's Track and Field Team Barred from Rio Olympics. Retrieved February 14, 2018, from https://www.nytimes.com/2016/06/18/sports/olympics/russia-barred-riosummer-olympics-doping.html

Sandomir, R. (2011, September 8). ESPN Extends Deal With N.F.L. for \$15 Billion. Retrieved February 14, 2018, from http://www.nytimes.com/2011/09/09/sports/football/espn-extends-deal-withnfl-for-15-billion.html 
Schuessler, J. (2016, September 2). Is the National Anthem Racist? Beyond the Debate Over Colin Kaepernick. Retrieved February 14, 2018, from https://www.nytimes.com/2016/09/03/arts/music/colin-kaepernick-nationalanthem.html

Scott, E. (2016, July 14). RNC speech not Tebow's first foray into politics. Retrieved August 29, 2017, from http://www.cnn.com/2016/07/14/politics/tim-tebowrepublican-national-convention/index.html

Solari, C. (2016, April 21). MSU athletics makes \$150 million deal with FOX Sports. Retrieved February 14, 2018, from https://www.lansingstatejournal.com/story/sports/college/msu/2016/04/21/ms u-athletics-makes-150-million-deal-fox-sports/83337378/

Turner, J. S. (2014). This is SportsCenter: a longitudinal content analysis of ESPN's signature television sports-news program from 1999 and 2009. Journal of Sports Media, 9(1), 45-70. doi:10.1353/jsm.2014.0001

Van Bibber, R. (2013, August 23). NFL reportedly pressed ESPN to nix concussion film. Retrieved August 29, 2017, from https://www.sbnation.com/nfl/2013/8/23/4650568/roger-goodell-espn-pbsconcussions-documentry-league-of-denial

Villeneuve, J., \& Aquilina, D. (2016). Who's fault is it? An analysis of the press coverage of football betting scandals in France and the United Kingdom. Sport In Society, 19(2), 187-200.

Wagner, L. (2018, January 25). Fox Sports Has Completely Ignored the Larry Nassar Sex Abuse Story. Retrieved February 14, 2018, from https://deadspin.com/foxsports-has-completely-ignored-the-larry-nassar-sex-1822415652

Wagoner, N. (2016, August 28). Colin Kaepernick protests anthem over treatment of minorities. Retrieved February 14, 2018, from http://www.espn.com/nfl/story/_/id/17401815/colin-kaepernick-san-francisco49ers-sits-national-anthem-prior-preseason-game

Walker, J. (2016, September 26). Jose Fernandez dies in boating accident. Retrieved February 14, 2018, from http://www.espn.com/mlb/story/_/id/17632541/miamimarlins-ace-jose-fernandez-dies-boating-accident

Wann, D., Schrader, M., \& Wilson A. (1999). Sport fan motivation: Questionnaire validation, comparisons by sport, and relationship to athletic motivation. Journal of Sport Behavior, 22(1). 
Whiteside, E., Yu, N., \& Hardin, M. (2012). The new "toy department"?: A case study on differences in sports coverage between traditional and new media. Journal of Sports Media, 7(1), 23-38. doi:10.1353/jsm.2012.0000

Williams, B. A., \& Delli Carpini, M. X. (2000). Unchained reaction: The collapse of media gatekeeping and the Clinton-Lewinsky scandal. Journalism, 1(1), 61-85.

Withey, S. (2013). Fan motivation for attendance to men's Division I college soccer matches. Clemson University.

Young, R. (2016, July 5). Kevin Durant to sign with Warriors. Retrieved February 14, 2018, from http://www.espn.com/nba/story/_/id/16759826/kevin-durantannounces-sign-golden-state-warriors 